\title{
DESAFIOS PARA GESTORES ESCOLARES EM TEMPOS DE INCERTEZA
}

\section{CHALLENGES FOR SCHOOL MANAGERS IN TIMES OF UNCERTAINTY}

\author{
Leila lannone $^{1}$
}

\section{RESUMO}

O presente artigo faz uma reflexão sobre os desafios da gestão escolar durante a pandemia da covid, aponta alguns caminhos que podem auxiliar o gestor e questionamentos que podem servir de base para os caminhos futuros em relação ao papel do gestor escolar. Para tanto, tem por pressupostos teóricos autores que apontam o caminho democrático e participativo como elucidadores das reflexões e sustenta-se em dados e pesquisas realizadas pelo Banco Mundial em 2021.

PALAVRAS-CHAVE: Educação. Gestão escolar. Pandemia

\section{ABSTRACT}

This article reflects on the challenges of school management during the covid pandemic, it proposes some paths that can help the manager and questions that can serve as a basis for future paths in relation to the role of the school manager. It's theoretical assumptions author's point to the democratic and participatory path as elucidators of reflections and is supported by data and research carried out by the World Bank in 2021.

KEYWORDS: Education. School management. Pandemic

\footnotetext{
1 Doutora em Educação (Currículo) pela PUC-SP (2002) com mestrado em Educação (Supervisão: Currículo) pela PUC-SP (1997), em Letras pela Faculdade de Filosofia Ciências e Letras Sedes Sapientiae (1971) e graduação em Pedagogia pelo Centro Universitários Assunção (1978). É coordenadora científica, desde 2017, da publicação TIC Educação -Pesquisa sobre o uso de Tecnologias de Informação e Comunicação em escolas brasileiras em Educação. Foi membro do Conselho Estadual de Educação de São Paulo, órgão do governo do Estado, (2004-2009) com atuação na Câmara de Educação Básica e na Câmara do Ensino Superior e Presidente da Comissão de Planejamento. Foi diretora de Projetos da Fundação para o Desenvolvimento da Educação-FDE e assessora de Gabinete do Secretário da Educação do Estado de São Paulo. Desenvolve assessoria para redes públicas e privadas de ensino, atuando em currículo em meio digital, gestão, avaliação e implantação de escolas. Desenvolveu pesquisas e Avaliações de programas e projetos para UNESCO Brasil e UNESCO do Uruguai.

Publicação mais recente (2019): lannone,L.R.; Soares. A.C. "Gestão da educação pública com uso de tecnologia digital" características e tendências .UNESCO Office in Brasilia .Brasília,2019 245p ISBN:978-85-7652-248-5 Disponível :https://unesdoc.unesco.org/ark:/48223/pf0000376914
} 


\section{Desafios para gestores escolares em tempos de incerteza}

A reflexão sobre o papel do gestor escolar será infrutífera se ignorar a abrangência de três verbos nucleares interdependentes e oportunos: organizar, mobilizar e articular. Essas ações envolvem todas as condições materiais e humanas para garantir o avanço dos processos socioeducacionais, cujo objetivo é a promoção da aprendizagem dos alunos. Há duas interpretações dessa proposição na visão de Lück $(2000)^{2}$, considerando diferentes níveis de gestão e respectivos espaços de responsabilidade.

A primeira destaca que a necessária aprendizagem dos alunos será efetiva, se consonante com as transformações do contexto, exigindo novas e complexas competências humanas, sinergicamente organizadas. Fruto da observação e análise das tendências do mundo em transformação à época da publicação, mas distante da mais fértil imaginação sobre os impactos da pandemia, as ponderações de Lück mostram-se atuais e indispensáveis para o momento de múltiplas rupturas no cenário das escolas, seja pela (des)territorialização da sala de aula, seja pelo impacto socioemocional dos tempos pandêmicos, pela incerteza dos cenários futuros e "errância"3 do currículo ou, ainda, pelo conjunto de todos esses fatores a exigir organização, mobilização e articulação de diferentes recursos pelos gestores em direção à aprendizagem efetiva dos alunos.

A segunda colocação provocativa de Lück, decorrente da primeira, é a necessidade de encontrar um modo de agir e fazer, caracterizado por ações que ultrapassem a ineficácia de "soluções tópicas", também verificáveis atualmente, que transitam ora por atualização de programas de formação de professores, ora pela aquisição de recursos tecnológicos (supostamente mais eficientes), ora pela introdução de novas metodologias (impulsionadas pela emergência de um currículo por competências), ora pela contratação de suporte psicológico para os professores, entre outras soluções imediatistas. Na realidade, se essas ações não forem orquestradas simultaneamente, a partir de um plano estratégico para abranger o conjunto complexo de problemas emergentes e a definição de uma agência em rede, requisitando os diversos gestores (diretor, coordenadores, supervisores, orientadores) nos seus respectivos espaços de atuação, será improvável a consecução da efetiva aprendizagem do aluno.

A revisão das práticas adotadas por gestores e gestoras deve levar em conta a integração e a sequência coerente das ações para que o aluno, ao final, participe do processo de aprendizagem com as condições necessárias para alcançar resultados exitosos.

Até que ponto, no encadeamento de ações das diferentes instâncias gestoras ou "espaços de governabilidade" (Gonçalves,2007, p.3) ${ }^{4}$ mantém-se a coerência entre o objetivo proposto e a consecução do propósito, considerando-se a possibilidade de controle de algumas variáveis e de outras não? Por que ocorre, muitas vezes, o descolamento do projeto inicial, ao longo da cadeia?

A experiência em avaliação de programas e projetos aponta, frequentemente, para o hiato de informações, omissão de procedimentos encadeados entre um espaço de governabilidade e outro, de modo que, ao se chegar ao aluno parte dos efeitos do plano inicial se perdeu.

Refletir sobre essa (des)organização ressalta a importância da liderança compartilhada, com atribuições claramente delegadas e definição de quais mecanismos e instrumentos de regulação serão utilizados para cada um dos gestores e para todos num continuum observável.

\footnotetext{
2 Lück, H.(org.) Gestão escolar e formação de gestores. Em Aberto. INEP: Brasília. v17, $n$.72, p.1-195 fev/jun2000 ${ }^{3}$ CASALI, A. Abertura: por um currículo errante. In: ALMEIDA, F. J.; ALMEIDA, M. E. B.; SILVA, M. G. M (org.). De Wuhan a Perdizes: Trajetos educativos [recurso eletrônico]. São Paulo: Educ, 2020. p. 10. Disponível em: https://www.pucsp.br/educ/downloads/trajetos_educativos.pdf. Acesso:30 julho 2021 Acesso: 5 ago 2021

${ }^{4}$ GONÇALVES, C.L. Gestão Participação :subjetividades em relação.Doutorado.Programa de Pós- graduação em Psicologia da Educação PUCSP 2007
} 
Quadro 1 - Etapas de gestão

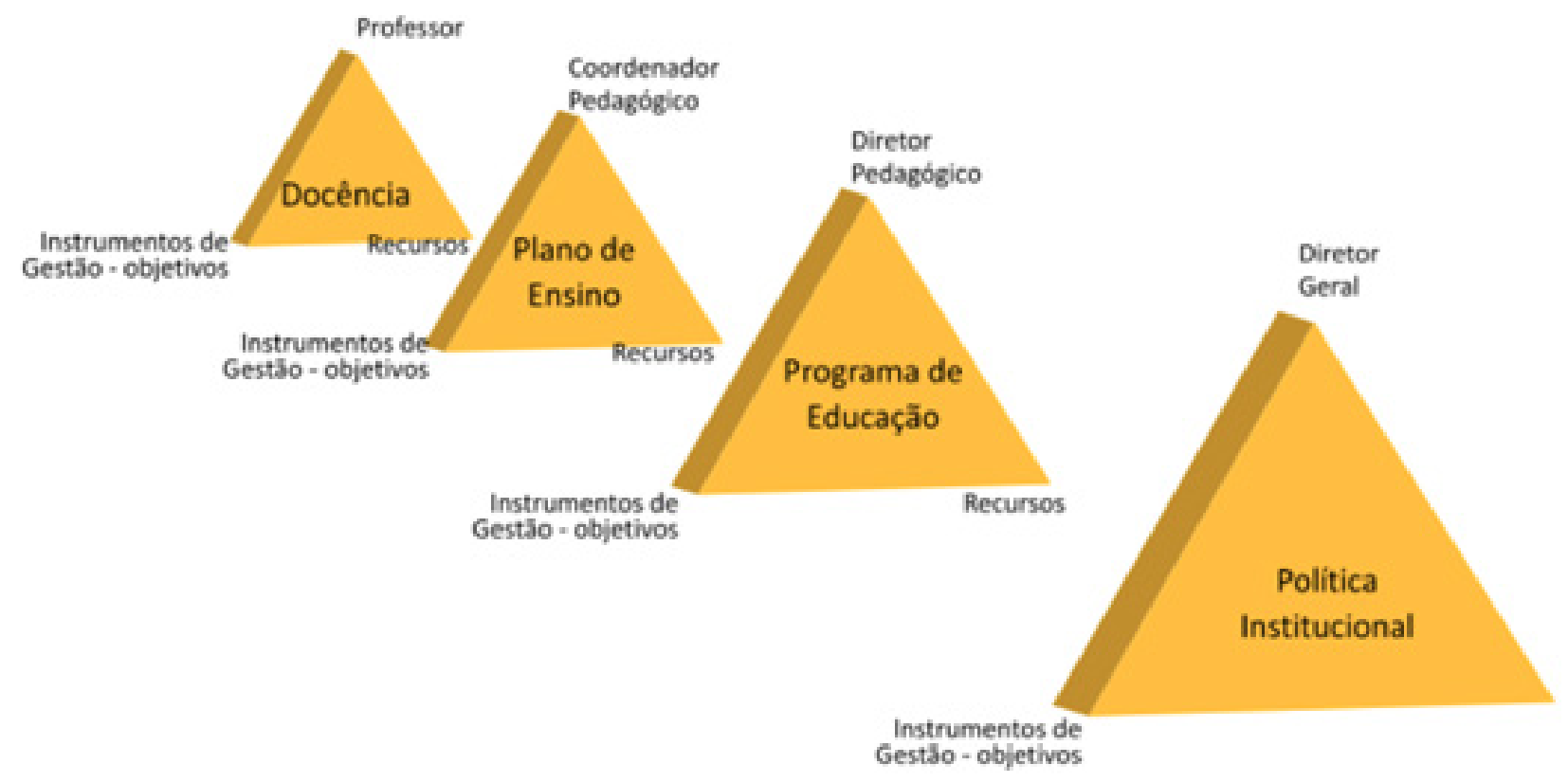

Fonte: elaborado pela autora

O diagrama acima foi inspirado em Spillane $(2006)^{5}$ que aponta, também, a responsabilidade coletiva dos gestores, quando sobre o mesmo tema de trabalho. Esclarece a necessidade de compartilhar a liderança e a gestão de processos complexos, levando em conta a complementaridade de saberes e competências em favor da consecução de objetivos comuns, no caso as melhores condições para a aprendizagem dos alunos.

\section{Profusão de necessidades e caminhos da gestão}

Os desafios da gestão, sempre com exigências múltiplas, foram acrescidos de complexidade com as intercorrências da pandemia. Independentemente da afinidade ou não com tecnologias, os profissionais da educação viram-se compelidos ao uso de ferramentas digitais para manter a comunicação, a supervisão de processos, o acompanhamento dos professores, entre outras demandas. As escolas que investiram previamente na cultura digital foram favorecidas de alguma maneira, pois seus educadores já dominavam um repertório de soluções, mesmo que ainda restrito. As que relegaram para o futuro os investimentos nessa área foram surpreendidos por um considerável conjunto de apelos, cuja solução dependeu e depende não só da gestão compartilhada, mas, também, de ferramentas ágeis, interconectadas e produtivas para permitir tal possibilidade de gestão.

É preciso adicionar a esta reflexão o fato de que a volta às aulas presenciais não permite o abandono das soluções digitais conquistadas no período de ensino remoto e híbrido. Em muitas localidades, as três modalidades convivem, sem data determinada para a suspensão definitiva de uma ou outra. E, para além dessa constatação, nenhuma escola que analise o cenário de incertezas a que a sociedade está exposta na área da saúde, abdicará da manutenção desses recursos para desenvolver atividades nas três hipóteses, seja para os alunos, seja para os educadores.

Toda sociedade reconhece que houve perdas em termos de aprendizagem e escolarização no período da pan-

${ }^{5}$ SPILLANE,J.Distibuted leardship ,2006 Figura 1.1.Leardship practice from distributed perspective. p 3 
demia. Uma estimativa do Banco Mundial $(2021)^{6}$ aponta que a América Latina e o Brasil têm uma perda média de 1,3 anos de escolaridade, se analisada sob o ponto de vista da qualidade da aprendizagem. $O$ estudo considera que um fechamento de escola durante dez meses pode aumentar de $55 \%$ para $71 \%$ o percentual de estudantes abaixo do nível mínimo de proficiência com a métrica do Programa Internacional de Avaliação de Estudantes (Pisa), exame trienal realizado pela Organização para a Cooperação e Desenvolvimento Econômico (OCDE). Se o fechamento for projetado para 13 meses, o percentual dos estudantes, abaixo desse nível mínimo, pode aumentar para 77\%.

No Brasil, a desigualdade de acesso à educação é estigmatizada pela profunda desigualdade, que recrudesceu com o ensino remoto. Resultados de Pesquisa do Instituto Península ${ }^{7}$ apontam, a partir de relatos dos professores, que os docentes das redes privadas de ensino ofereceram suporte a distância aos estudantes em percentual significativamente maior do que aqueles ligados às redes dos estados e municípios. A pesquisa ainda demonstra que, até a data de paralisação das aulas presenciais, $88 \%$ dos respondentes nunca tinham ministrado aula de forma remota e que, mais da metade (56\%) dos docentes consultados passaram por alguma mudança na situação de trabalho devido à crise do novo coronavírus, especialmente os da rede privada.

Por outro lado, na perspectiva positiva, o ensino remoto, que antes era uma ideia distante, tornou-se parte do cotidiano e de forma surpreendente. Os professores adaptaram-se e perceberam, gradativamente, que a tecnologia poderia tornar-se aliada da aprendizagem. Entre tantos condicionantes elencados, e outros além desses, os gestores precisam gerir processos e garantir um ritmo adequado à aprendizagem.

Não há receitas prontas, mas certamente os educadores estão mais próximos do uso de recursos digitais, o que pode aperfeiçoar e abreviar o tempo dedicado a registros, mapas comparativos, extração de relatórios, possibilitando a identificação de ajustes necessários, reforço nos pontos exitosos e agilidade de providências para os pontos de atenção. Os instrumentos de gestão disponíveis em plataformas e soluções adaptativas podem mapear necessidades de formação, garantir encontros produtivos para a resolução de problemas, contribuir para ajustar e/ ou refinar questões do desenvolvimento curricular, se e quando os gestores se apropriarem adequadamente de seu funcionamento e construírem interlocução fértil nesse banco de dados.

Nenhum médico se preocupa em classificar seus pacientes, do menos doente ao mais gravemente atingido. Nem mesmo pensa em Ihes administrar um tratamento coletivo. Esforça-se para determinar, para cada um deles, um diagnóstico individualizado, estabelecendo uma ação terapêutica sob medida (PERRENOUD ,1999 p 15).

Entretanto, novamente, é impossível ignorar a considerável distância de condições das redes pública e privada. Na rede pública, os professores, durante o isolamento social, comunicaram-se quase que unicamente por meio da ferramenta WhatsApp, deixando alunos, famílias e educadores sem informações qualificadas para manutenção do processo escolar em bases aceitáveis. Essa realidade merece estudos mais alentados para que haja um encaminhamento eficiente de políticas públicas e o resgate gradativo das condições de aprendizagem e a superação da queda da proficiência, como abordada no início deste artigo.

Já, na rede privada, houve adoção de diferentes ferramentas tecnológicas contribuindo para a melhor interação entre professores e alunos. E, certamente, a disponibilidade de recursos favoreceu a comunicação e orientação dos docentes e técnicos, a distribuição fundamentada de informações às famílias e a manutenção de vínculos com os alunos.

Além de sites ativos e atualizados, as escolas aprimoraram a comunicação via plataformas digitais e, entre os

\footnotetext{
${ }^{6}$ Banco Mundial. (2021). Agindo agora para proteger o capital humano de nossas crianças: Os custos e a resposta ao impacto da pandemia de COVID-19 no setor de educação na América Latina e Caribe. Disponível:https://openknowledge.worldbank.org/bitstream/handle/10986/35276/ Acting\%20now-sumPT.pdf Acesso:5 agos 2021

${ }^{7}$ Instituto Península. (2020). Sentimento e percepção dos professores nos diferentes estágios do coronavírus no Brasil. Disponível: https://institutopeninsula.org.br/pesquisa-sentimento-e-percepcao-dos-professores-nos-diferentes-estagios-do-coronavirus-no-brasil/ Acesso:2 agos 2021
} 
amplos recursos, pode-se destacar:

a) Facebook/Instagram: diminuiu a sensação de distâncias e promoveu a manutenção de vínculos com divulgação de momentos de confraternização. Transformou-se num instrumento de gestão da comunicação e de pessoas ao fornecer dados sobre o posicionamento de famílias e alunos, além de números de acessos para que a escola estabelecesse a "métrica da audiência" ,revelando a proximidade e/ou distanciamento do vínculo com a comunidade educativa.

b) Linkedin: a rede social profissional foi utilizada, para recrutamento de profissionais como reforço das equipes, especialmente, na área de TÊ; conteúdos publicados sobre segurança sanitária e outros documentos em circulação, promoveram trocas que reforçaram a imagem das escolas como detentoras de informações diante da comunidade educativa. Pode-se dizer que se transformou num instrumento de gestão da informação no âmbito de relações profissionais.

c) IsCoolApp: Aplicativo destinado à comunicação com os pais, responsáveis e colaboradores sobre qualquer acontecimento na escola; utilizado para lembretes, postagens institucionais, divulgação de pesquisas e eventos, convites, comunicados e avisos; utilizado para oitiva sobre eventos, serviços oferecidos ou qualquer outra necessidade de mensurar, aferir em dados quantitativos, a opinião da comunidade. Uma das funções mais importantes foi manter calendários e grades horárias atualizados para todos os segmentos de ensino, durante todo o todo o ano letivo, condição essencial para orientação de todos num cenário de adaptações. Nessa perspectiva, o aplicativo foi instrumento eficaz na gestão da comunicação e de processos.

Foram inúmeras as possibilidades para a comunicação em meio digital que articularam o setor pedagógico aos da tecnologia educacional, da comunicação e da saúde, além das apresentadas, criando oportunidades para o desenvolvimento de cultura digital.

Na medida em que a informação atualizada e sistemática chegou às respectivas comunidades, expressou também a filosofia, os princípios e a intencionalidade educativa da escola, reforçando a articulação da imagem à missão, à visão e ao ideário educacional. A gestão dos recursos, portanto, foi fundamental para que o processo educativo não fosse interrompido e o posicionamento da escola diante da conturbada discussão sobre a reabertura ou não das unidades escolares, sobre os ajustes pedagógicos, especialmente na Educação Infantil, não fossem ignorados, mas tratados com objetividade e presteza.

Finalmente, os recursos digitais foram importantes na divulgação dos protocolos sanitários e para a informação sobre as novas dinâmicas escolares, junto a alunos, famílias, professores e agentes educativos.

Retome-se, neste ponto, a reflexão inicial e o resgate das palavras: organizar, mobilizar e articular. Elas inspiram a conveniência de uma autoavaliação da gestão e dos gestores, a partir de algumas perguntas mobilizadoras:

O quanto a gestão com uso de tecnologias aproximou os espaços de governabilidade e os diferentes gestores? As responsabilidades partilhadas e ações sequenciadas dos gestores propiciou condições para a melhor aprendizagem dos alunos? Quais os instrumentos de gestão oferecidos pela tecnologia permanecerão em uso e quais serão substituídos para consecução dos objetivos diante das necessidades dos alunos?

\section{REFERÊNCIAS}

ALMEIDA, M. E. B. de. A crise educacional gerada pela Covid 19 e as tecnologias: ontem, hoje os caminhos para o futuro. In: ALMEIDA, F. J.; ALMEIDA, M. E. B.; SILVA, M. G. M (org.). De Wuhan a Perdizes: Trajetos educativos [recurso eletrônico]. São Paulo: Educ, 2020. p 164-179. Disponível em: <https://www.pucsp.br/educ/downloads/ trajetos_educativos.pdf>. Acesso em: 18 mar. 2021.

BACICH, L.; TANZI NETO, A.; TREVISANI, F. de M. (org.). Ensino híbrido: personalização e tecnologia na educação. Porto Alegre: Penso, 2015. 
CASTELLS, M. Internet e sociedade em rede. In: MORAES, D. (org.). Por uma outra comunicação. Rio de Janeiro: Record, 2003.

FULLAN, M.; HARGREAVES, A. A escola como organização aprendente. Porto Alegre: Artmed, 2000.

IANNONE, L. R.; ALMEIDA, M. E. B.; VALENTE, J. A. Pesquisa TIC Educação: da inclusão para a cultura digital. In: Comitê Gestor da Internet no Brasil - CGI.BR. Pesquisa sobre o uso das tecnologias da informação e comunicação nas escolas brasileiras: TIC Educação 2015. São Paulo: CGI.br, 2016. p. 55-67.

KENSKI, V. M. Educação e tecnologias: um novo ritmo da informação. 8. ed. Campinas: Papirus, 2012.

LUCAS, M.; MOREIRA, A. DigCompEdu: Quadro Europeu de Competência Digital para Educadores. Aveiro: UA Editora - Universidade de Aveiro, 2018. Disponível em: <http://area.dge.mec. pt/download/DigCompEdu_2018. pdf>. Acesso em: 20 fev. 2021.

LÜCK, H. Perspectivas da gestão escolar e implicações quanto à formação de seus gestores. Em Aberto, Brasília, v. 17, n. 72, p. 1-195, fev./jun. 2000. Disponível em: <http://www.crmariocovas.sp.gov.br/pdf/em_aberto_72.pdf>. Acesso em: $12 \mathrm{abr} .2021$.

NÓVOA, A. Os professores na virada do milênio: do excesso dos discursos à pobreza das práticas. Cuadernos de Pedagogía, n. 286, dez. 1999. Disponível em: <http://repositorio.ul.pt/bitstream/10451/690/1/21136_1517-9702_. pdf>. Acesso em: 20 dez. 2020.

VALENTE, J. A. O papel da mediação e da interação na educação a distância: estabelecendo estratégias diferenciadas de ensino. In: Trindade, M. A. B. (org.). As tecnologias da informação e comunicação (TIC) no profissional de trabalhadores do SUS. São Paulo: Instituto da Saúde, 2011.

${ }^{10} \mathrm{http}: / /$ www.sdh.gov.br/noticias/2016/maio/disque-100-recebe-quase-cinco-mil-denuncias-de-violencia-sexual-contra-criancas-e-adolescentesnos-primeiros-quatro-meses-de-2016. Acesso em 23 de abril de 2018 